\title{
Magnetic fraction in atmospheric aerosols in Krakow (Poland)
}

W. WILCZYŃSKA-MICHALIK ${ }^{1 *}$, J.M. MICHALIK ${ }^{2}$, W. TOKARZ ${ }^{2}$, J. ŻUKROWSKI ${ }^{4}$, M. GAJEWSKA ${ }^{4}$, M. MICHALIK ${ }^{5}$

${ }^{1}$ Pedagogical University of Krakow, Institute of Geography, Krakow, Poland (*correspondence: wanda.wilczynskamichalik@up.krakow.pl)

${ }^{2}$ AGH-University of Science and Technology, Faculty of Physics and Applied Computer Science, Krakow (jmichali@agh.edu.pl, tokarz@uci.agh.edu.pl)

${ }^{4} \mathrm{AGH}-$ University of Science and Technology, Academic Centre for Materials and Nanotechnology, Krakow (marta.gajewska@agh.edu.pl, zukrow@agh.edu.pl)

${ }^{5}$ Jagiellonian University, Institute of Geological Sciences, Krakow (marek.michalik@uj.edu.pl)

Magnetic fraction of atmospheric aerosols was collected during 9 months period (2019-2020) in Kraków which is among cities with very high level of athmospheric pollution. Precise determination of the origin of magnetic particles in atmospheric aerosols is difficult however high content of particles from anthropogenic sources is evident. Fe (and other metals) rich particles possess different environmental impacts and adverse human health effects.

A static sampler - a matrix of solid magnets arranged to increase gradients and magnetic field strenght was used. Magnetic fraction was analyzed using SEM-EDS, TEM, VSM under applied field and as a function of temperature as well as Mössbauer spectroscopy.

Magnetic fraction is dominated by particles rich in $\mathrm{Fe}$ and containing small amounts of other transition metals in various proportions $(\mathrm{Cr}, \mathrm{Zn}, \mathrm{Cu}, \mathrm{Mn}, \mathrm{Ni})$. Particles with domination of other metals (e.g., $\mathrm{Pb}, \mathrm{W}$ or $\mathrm{Au}$ ) are scarce. Fe rich particles occur as discrete forms of various size and morphology, grains attached to the surface of bigger particles (e.g. quartz, feldspar, various aluminoslicates, gypsum) or their aggregates. Fe rich particles occur also as component of aggregates of various size and morphology. Fe rich particles are characterized bay various content of $\mathrm{O}$.

Fe rich particles varies in size from above $20 \mu \mathrm{m}$ (rarely) to nanoparticles below $100 \mathrm{~nm}$. Particles with diameter from 5 to $0.5 \mu \mathrm{m}$ occur commonly as irregular or sperical forms and below $500 \mathrm{~nm}$ are usually spherical and occur in clusters.

Magnetization measurements show clearly a strong ferromagnetic signal saturating at about $0.4 \mathrm{~T}$.

Acknowledgements. Research was supported within subsidy of Ministry of Science and Higher Education (statutory tasks) by the Universities listed in affiliations. 